\title{
Leuconostoc mesenteroides Growth Kinetics with Application to Bacterial Profile Modification
}

\author{
Raymond E. Lappan and H. Scott Fogler* \\ Department of Chemical Engineering, The University of Michigan, \\ Ann Arbor, Michigan 48109-2136
}

Received July 8, 1993/Accepted November 1, 1993

Bacterial profile modification (BPM) is being developed as an oil recovery technique that uses bacteria to selectively plug oil depleted zones within a reservoir to divert displacing fluids (typically water) into oilrich zones. Leuconostoc mesenteroides, which produces dextran when supplied with sucrose, is a bacterium that is technically feasible for use in profile modification. However, the technique requires controlled bacterial growth to produce selective plugging.

A kinetic model for the production of cells and polysaccharides has been developed for $L$. mesenteroides bacteria. This model, based on data from batch growth experiments, predicts saccharide utilization, cell generation, and dextran production. The underlying mechanism is the extracellular breakdown of sucrose into glucose and fructose and the subsequent production of polysaccharide (dextran). The monosaccharides are then available for growth. Accompanying sucrose consumption is the utilization of yeast extract. The cell requires a complex media that is provided by yeast extract as a source of vitamins and amino acids. Varying the concentration ratio of yeast extract to sucrose in the growth media provides a means of controlling the amount of polymer produced per cell. Consequently, in situ bacteria growth can be controlled by the manipulation of nutrient media composition, thereby providing the ability to create an overall strategy for the use of $L$. mesenteroides bacteria for profile modification. (c) 1994 John Wiley \& Sons, Inc. Key words: Leuconostoc mesenteroides - dextran • kinetics - bacterial profile modification

\section{INTRODUCTION}

Bacteria can be used beneficially for oil recovery by exploiting their ability to grow in situ, resulting in the reduction of local reservoir permeability. ${ }^{6}$ The benefit would be evident if water-swept zones, zones in the reservoir devoid of oil due to earlier displacement of oil by water, are plugged to prevent further conduction of injection water. This plugging would force injection fluids into oil-bearing zones and result in an increase in the oil production yields from the reservoir. For the remainder of the paper such a technique will be called bacterial profile modification (BPM).

Evidence of the technical feasibility of using bacteria to selectively plug a reservoir was realized by the authors during an initial study of formation damage due to

\footnotetext{
* To whom all correspondence should be addressed.
}

bacterial growth. ${ }^{8}$ This study focused on understanding the mechanism for permeability reduction due to in situ bacterial growth. It was found that a major contributor to the problem of injection well plugging was the ability of various indigenous and unintentionally injected bacteria to produce extracellular polysaccharides. The polysaccharides, which are cellular polymers used by cells for adhesion to surfaces and for nutrient storage, allow the cell to be retained within the interstitial surfaces of the porous subsurface. This retention decreases the void space and increases fluid transport resistance.

Leuconostic mesenteroides was used for comparative in situ growth experiments in which bacterial polysaccharide (dextran) production was either induced or suppressed by the presence or absence of sucrose in the growth media, respectively. The results from in situ growth experiments are presented in Figure 1 and detailed elsewhere. ${ }^{8}$ The data demonstrate the effect of the cellular polysaccharides on plugging of the porous media, as shown by the significant reduction of the porous media permeability only when polymers were produced.

A parallel core plugging experiment was subsequently carried out to determine the ability of the cells to plug selectively the high permeability core. Here, fluid flow was split into high and low permeability cores that were connected in parallel. Figure 2 presents the resulting ratio of the flow rate through the low permeability core relative to that through the high permeability core, $\left(Q_{l} / Q_{h}\right)$, as a function of time during constant volumetric sucrose feed. The experiment started with the injection of $L$. mesenteroides in a glucose-fructose media followed by injection of the sucrose feed. Throughout the experiment there was no manipulation of the fluid injection control, i.e., the core samples were the sole controllers of fluid movement. The data illustrate the ability of the bacteria to divert the feed solution from the high permeability core into the low permeability core. This diversion was the result of biomass generation in the high permeability core. However, with additional nutrient injection, the system exhibited a maximum flow diversion followed by a degeneration of the flow diversion. This degeneration is believed to be the result of cell growth in the low permeability core. These results demonstrate that bacteria can be used for BPM. However, the control of when and where plugging occurs within 


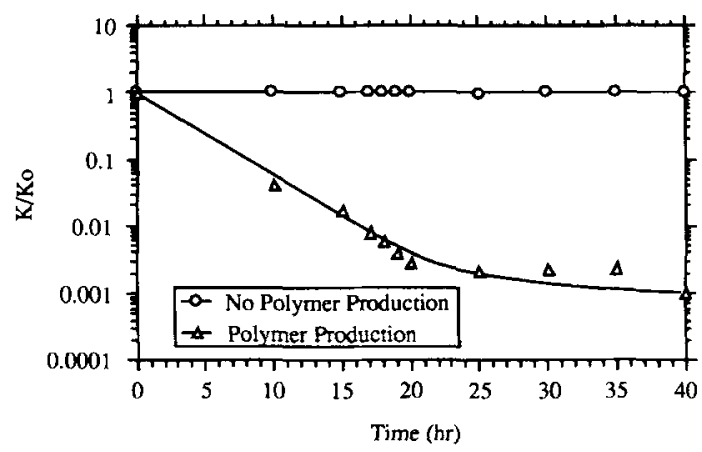

Figure 1. Permeability reduction due to dextran synthesis in high permeability core (14.7 Darcies with median pore throat size of $33 \mu \mathrm{m}$ ).

the reservoir proves to be of critical importance because diversion of fluid from the high permeability core was not maintained. To maintain and control this diversion requires information regarding the growth and dextran production rates for $L$. mesenteroides, which is the focus of this study, and an understanding of cell transport and retention in the porous media.

\section{MATERIALS AND METHODS}

Continuously stirred batch experiments were conducted to determine L. mesenteroides (ATCC 14935) and polysaccharide (dextran) production and nutrient consumption rates. Typically reactor volumes varied from 0.5 to $0.8 \mathrm{~L}$. Reactor temperatures were maintained at a constant $24 \pm 1{ }^{\circ} \mathrm{C}$. Inoculum used in the kinetic studies did not have more than three media transfers in order to prevent phenotypic alterations of the bacteria. Bacteria with less than three media transfers exhibited very short lag times of less than $1 \mathrm{~h}$ during growth experiments lasting 10 to $12 \mathrm{~h}$. The media used to grow the inoculum was a combination of glucose-fructose and yeast extract, as presented in Appendix I. The inoculum for the mechanism determination experiments consisted of culture cells grown for 18 to $24 \mathrm{~h}$ on the glucose and fructose media (the stationary phase for growth). All other experiments used inoculum that was further processed by separating the cells by centrifugation from their original media before being transferred into the batch reactors.

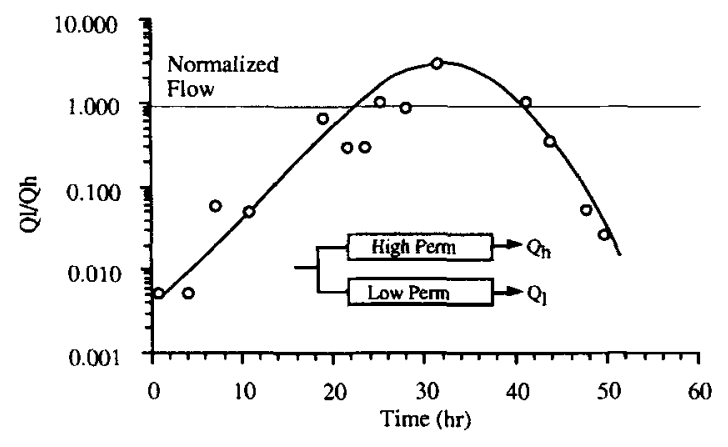

Figure 2. Low permeability to high permeability flow ratio for parallel core experiments, Par-3.
The cell concentrations were determined spectrophotometrically (light scattering) for substrate preference experiments, whereas for all other experiments the cell concentrations were determined with a Coulter counter. Sucrose, fructose, and glucose were also monitored throughout the experiments. Glucose concentrations in the supernatant were determined by using a hexokinase-dehydrogenase assay, ${ }^{1}$ and the sum of fructose and glucose concentration was determined by the dinitrosalicylic acid assay. Sucrose concentrations in supernatant were determined by adding invertase to hydrate the disaccharide, thus producing glucose and fructose that were then assayed using the dinitrosalicylic acid assay. Both cell and saccharide concentrations were determined in triplicate. Amino acid concentrations were determined by high performance liquid chromatograph (C-18 reverse-phase column packed with bonded phase silica from Applied Biosystems).

The insoluble dextran concentrations were determined by using dextransucrase to break the dextran molecules into soluble oligosaccharide. Pellets were first washed three times and suspended in $0.1 M$ phosphate buffer solution ( $\mathrm{pH}$ 6.0) to remove impurities such as soluble reducing sugars. Next dextranase (EC 3.2.1.11 Sigma Grade III in $0.1 M$ phosphate buffer) was added and incubated at $37^{\circ} \mathrm{C}$ to break down the insoluble dextran into soluble oligosaccharides. The suspensions were then centrifuged to separate the cells from the soluble oligosaccharides. The concentration of oligosaccharides in the supernatant was analyzed with a phenol-sulfuric acid assay detailed by Chaplin. ${ }^{1}$ These dextran assays were determined in triplicate.

Measurements of the activity of sucrose reducing enzyme(s), measured as free or suspended enzymes, were carried out by taking cell suspension samples during cell growth, centrifuging the sample at $14,000 \mathrm{~g}$ for $10 \mathrm{~min}$, and adding a buffered sucrose reagent solution (acetic acid buffer $\mathrm{pH} 5.2$, assay temperature $30 \pm 1{ }^{\circ} \mathrm{C}$ ) to the resulting supernatant, as detailed by Lawford. ${ }^{9}$ Initial $(t=$ $0.0 \mathrm{~min}$ ) and final $(t=50.0 \mathrm{~min})$ fructose and glucose concentrations were determined, in triplicate, using the procedure detailed earlier.

\section{THEORY}

A complex media is required for growth of $L$. mesenteroides. For this study, the media consisted of yeast extract, mono- or disaccharides, trace minerals, and a buffer (see Appendix I). Yeast extract was provided as a carbon source and as a source of growth factors. Saccharides were provided to the cells as both a carbon and energy source. The overall anaerobic metabolic reactions for sucrose (not stoichiometrically balanced), glucose, and fructose are well documented $^{11}$ and are as follows:

$$
\begin{aligned}
\text { Sucrose } & \longrightarrow \text { polysaccharide }(\text { dextran }) \\
+ \text { ethanol }+ \text { acetate }+ \text { mannitol }+ \text { lactate } & +\mathrm{CO}_{2} \\
& + \text { glucose }+ \text { fructose }
\end{aligned}
$$




$$
\text { Glucose } \longrightarrow \text { ethanol }+ \text { lactate }+\mathrm{CO}_{2}
$$

$$
\begin{aligned}
3 \text { Fructose } \longrightarrow 2 \text { mannitol }+ & \mathrm{CO}_{2} \\
+ & \text { acetate }+ \text { lactate }
\end{aligned}
$$

These overall reactions describe how the cell metabolizes the various saccharides to produce cell mass, dextran, and final metabolic products. However, these equations do not provide information on the intermediate reactions that govern the growth kinetics of the bacterium.

Dextran production by $L$. mesenteroides is catalyzed by the enzyme dextransucrase, represented as $E$ in the following equations.

$$
\begin{array}{ll}
\text { Sucrose } \stackrel{E}{\longrightarrow} \text { dextran }+ \text { fructose } \\
\text { Sucrose } \stackrel{E}{\longrightarrow} \text { glucose + fructose }
\end{array}
$$

This enzyme converts sucrose to dextran [Eq. (4)] in addition to a substantial amount of glucose [Eq. (5)] as found by Lawford et al.

\section{Modeling}

For mathematical simplicity, the Monod model for multiple limiting growth nutrients has been selected to describe the functionality of the specific growth rate. For multiple growth-limiting nutrients, this model is expressed as:

$$
\mu=\mu_{\max } \prod_{i=1}^{n} \frac{C_{i}}{K_{i}+C_{i}}
$$

where

$$
\begin{aligned}
\mu & =\text { specific growth rate }\left(\mathrm{h}^{-1}\right) . \\
\mu_{\max } & =\text { maximum specific growth rate }\left(\mathrm{h}^{-1}\right) . \\
n & =\text { number of limiting components. } \\
C_{i} & =\text { concentration of limiting component } i(\mathrm{~g} / \mathrm{L}) . \\
K_{i} & =\text { Monod constant for component } i(\mathrm{~g} / \mathrm{L}) .
\end{aligned}
$$

Ebert $^{2}$ and Lawford ${ }^{9}$ have developed a model that describes batch production of dextran, fructose, and glucose. This model follows the generalized form:

$$
r_{i}=\mathrm{V}_{\max _{i}}\left(\frac{C_{s}}{K_{d}+C_{s}}\right)
$$

where

$$
\begin{aligned}
r_{i}= & \text { rate of product } i \text { formation per unit volume } \\
& (\mathrm{g} / \mathrm{L} \cdot \mathrm{h}) . \\
V_{\max _{i}}= & \text { maximum velocity for species } i(\mathrm{~g} / \mathrm{L} \cdot \mathrm{h}), \\
& \left(\text { dependent upon enzyme concentration, } C_{e}\right) . \\
K_{d}= & \text { Michaelis - Menten constant }(\mathrm{g} / \mathrm{L}) . \\
C_{s}= & \text { sucrose concentration }(\mathrm{g} / \mathrm{L}) .
\end{aligned}
$$

This equation expresses the dependency of product $i$ production rate (i.e., dextran, glucose, or fructose) on the sucrose and enzyme concentrations.

Enzyme production is modeled by the general product formation equation given by Leudeking and Piret. ${ }^{10}$ This equation assumes product formation is the result of both growth- and non-growth-associated contributions:

$$
r_{i}=Y_{i / x} r_{x}+k_{i} C_{x}
$$

where:

$Y_{i / x}=$ growth-attributed product $i$ constant $(\mathrm{g} / \mathrm{cell})$.

$k_{i}=$ non-growth-attributed product $i$ constants $\left(\mathrm{h}^{-1}\right)$.

$r_{x}=$ rate of cell production $(\mathrm{g} / \mathrm{L} \cdot \mathrm{h})$.

$C_{x}=$ cell concentration (cells $/ \mathrm{L}$ ).

Eq. (8) can also be used to describe the corresponding consumption of nutrients that accompanies cell growth. In this situation, $Y_{i / x}$ is the yield coefficient and $k_{i}$ is the amount of substrate required for cell maintenance.

\section{RESULTS AND DISCUSSION}

Four key experiments, using various combination of sucrose, fructose, and/or glucose and yeast extract as growth media, were conducted to formulate a reaction mechanism and a kinetic model for cell growth on sucrose. Additional sucrose growth batch experiments were then used to determine the functionality and parameter values of the specific growth rate, the dextran production rate, and the nutrient consumption rate laws.

\section{Growth Experiments to Determine Substrate Utilization Mechanism}

The effect of sucrose, or glucose and fructose, on the cell growth rate was examined by conducting two batch reactor experiments. One batch experiment used a growth media containing yeast extract and sucrose, whereas in the other experiment the reactor media contained yeast extract, glucose, and fructose. To make the growth media equivalent in saccharide content, $7.9 \mathrm{~g} / \mathrm{L}$ of each glucose and fructose were added to one reactor, and sucrose was added at a concentration of $15.0 \mathrm{~g} / \mathrm{L}$ to the other. Appendix I lists the recipes used for the kinetic experiments. Figure 3 shows the cell densities as a function of time for the two batch cultures. As seen in Figure 3, the cell's growth was virtually the same in each case. These results, which have been duplicated, were expected because the two feeds used in the batch experiments were stoichiometrically equivalent.

Figure 4 presents the results of cells grown in a mediacontaining yeast extract, glucose, and fructose and shows

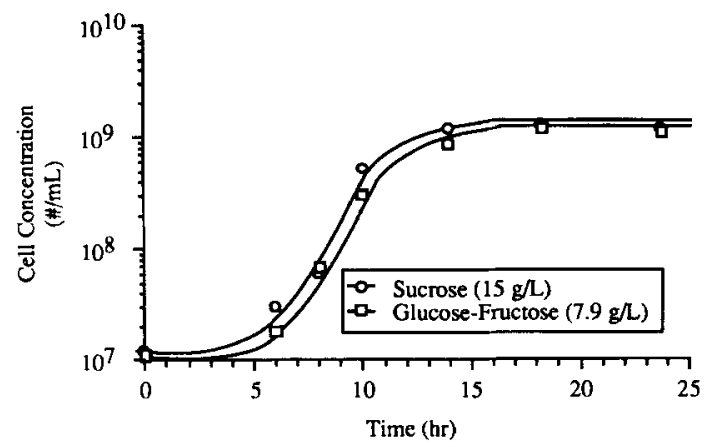

Figure 3. Dependency of the cell growth rate on a sucrose and glucose-fructose medium ( $15 \mathrm{~g}$ sucrose $/ \mathrm{L}, 7.9 \mathrm{~g}$ glucose/L, and $7.9 \mathrm{~g}$ fructose/L). 


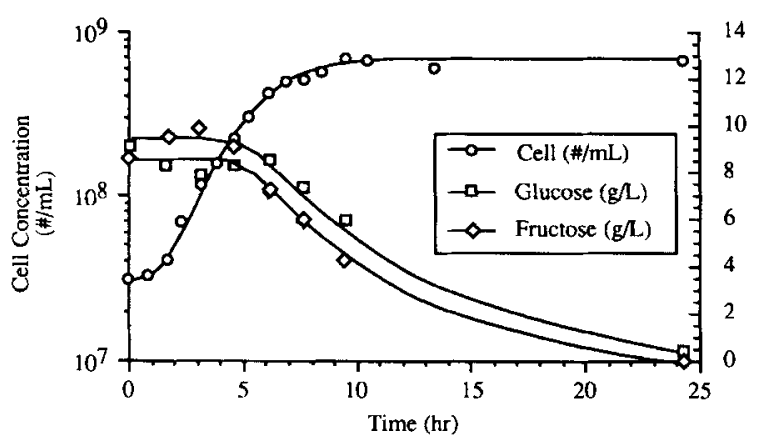

Figure 4. Cell growth on glucose and fructose, $10 \mathrm{~g}$ yeast extract/L.

that the consumption of glucose and fructose occurs simultaneously. As shown in Figure 4, the concentration of fructose begins to decrease $6 \mathrm{~h}$ after inoculation, as that of glucose begins to decrease approximately $7.5 \mathrm{~h}$ after inoculation. These results demonstrate the ability of the cells to consume both glucose and fructose simultaneously and not preferentially

A batch experiment was carried out to determined whether sucrose or glucose is consumed preferentially. The growth medium used for this experiment initially contained the two saccharides and yeast extract. As illustrated in the Figure 5, the cells consume almost all the sucrose before they begin to consume glucose. In fact, the concentration of glucose increases with time as the cells consume sucrose. This increase in glucose concentration and the appearance of fructose in the bulk solution is the result of sucrose metabolism for growth and dextran production.

As a result of the four experiments, a substrate utilization mechanism, presented in Figure 6, was developed. The mechanism predicts the external catabolism of sucrose to produce dextran, glucose, and fructose. The monosaccharides are then transported into the cell as nutrients for growth.

\section{Specific Growth Rate Experimental Results}

In this study, the dependency of the specific growth rate, $\mu$, on the concentration of the yeast extract and sucrose was determined. Figure 7 shows the initial specific growth

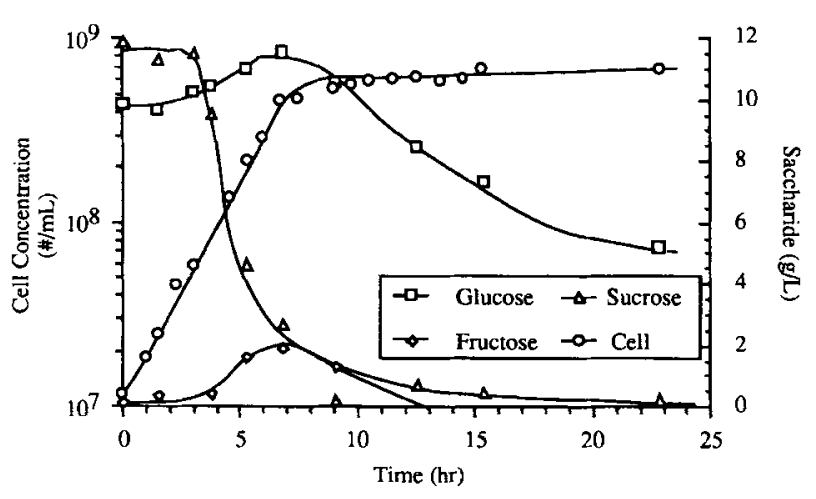

Figure 5. Cell growth on sucrose and glucose, $2 \mathrm{~g}$ yeast extract/L.
Substrate Utilization Mechanism

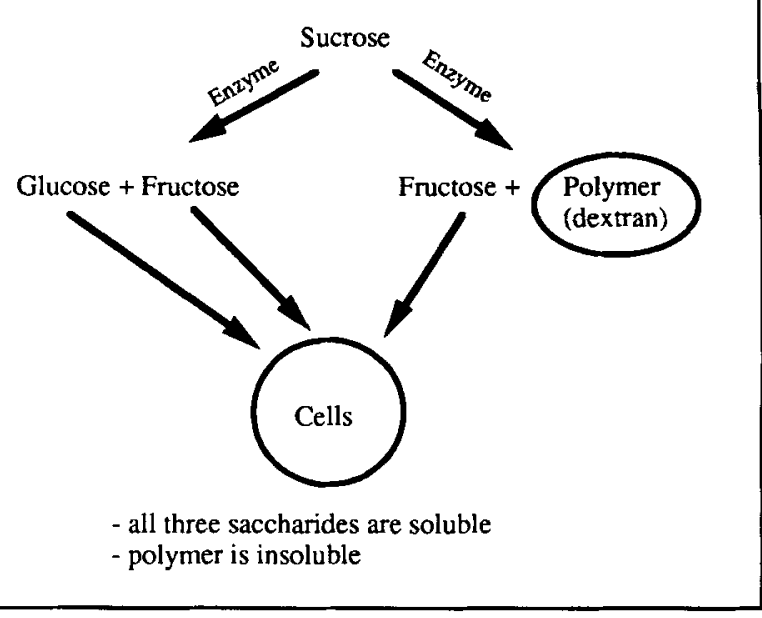

Figure 6. Substrate utilization mechanism.

rates as a function of the initial sucrose (and yeast extract) concentration for two series of batch growth experiments. Note that the initial specific growth rate was calculated using cell growth data under the conditions where the sucrose concentration of the media did not change appreciably. Both data sets show an initial growth on yeast extract nutrient media alone, with increases in the specific growth rate as sucrose concentrations are increased.

The initial specific growth rate, $\mu$, is shown in Figure 8 as a function of the initial yeast extract concentration without any sucrose present. These batch experiments contained a medium of trace mineral, as detailed in Appendix I, and varying yeast extract concentrations. As can be seen, the specific growth rate of the cells on yeast extract alone approaches a maximum value at yeast extract concentrations greater than $10 \mathrm{~g}$ yeast extract/L. Because yeast extract is itself a complex mixture containing amino acids, vitamins, purines, and pyrimidines, it was expected that one or more components in the yeast extract were limiting cell growth. A comparison of the components needed by cells for growth $^{11}$ with the components found in yeast extract (Difco Laboratories, Detroit, MI) gave the estimate that amino

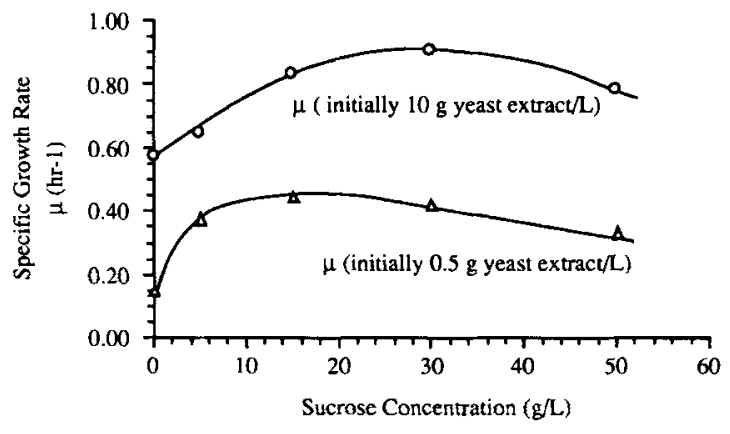

Figure 7. Specific growth rate as determined by batch culture experiments in media composed of varying sucrose concentrations and 10 or $0.5 \mathrm{~g}$ yeast extract $/ \mathrm{L}$. 


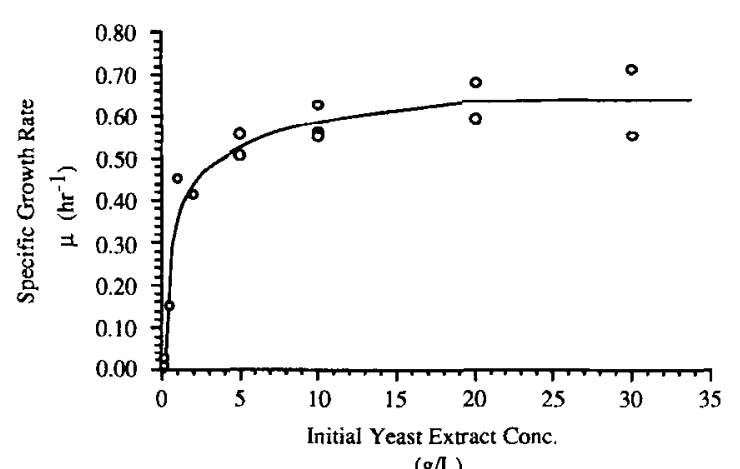

(g/L)

Figure 8. Specific growth rate constant as a function of yeast extract.

acids are the chemical species that would limit growth. Samples from three batch experiments were analyzed for free amino acids to determine which amino acids were being consumed to the greatest extent and thus limiting cell growth. The results from these amino acid assays also allowed for determination of a minimal yeast extract to sucrose ratio of $0.14 \mathrm{~g}$ yeast extract/g sucrose needed by the cell for growth. This value is based on the relative amount of sucrose to isoleucine consumed. Isoleucine had the highest conversion of all the 20 amino acids assayed. ${ }^{7}$

\section{Specific Growth Rate Model}

The following assumptions were used in the development of a two-parameter model:

1. The yeast extract, which contains an array of complex nutrients, is represented by the bulk concentration in the specific growth rate model.

2. Sucrose growth inhibition is neglected.

Because the yeast extract does not provide the same carbon constant per unit mass as sucrose, the multiple limiting nutrient concentration model can be reduced to:

$$
\mu=\mu_{\max }\left(\frac{C_{y e}}{K_{y e}+C_{y e}}\right)\left(\frac{\alpha C_{y e}+C_{s}}{K_{s}+\alpha C_{y e}+C_{s}}\right)
$$

where:

$$
\begin{aligned}
C_{y e}= & \text { yeast extract concentration }(\mathrm{g} / \mathrm{L}) . \\
C_{s}= & \text { sucrose concentration }(\mathrm{g} / \mathrm{L}) . \\
\alpha= & \text { yeast extract conversion factor (g sucrose/g } \\
& \text { yeast extract). }
\end{aligned}
$$

$K_{y e}$ and $K_{s}$ are the respective Monod constants for yeast extract and sucrose, respectively $(\mathrm{g} / \mathrm{L})$.

The kinetic parameters in Eq. (9) were determined from the experimental results using the method of least-squares error minimization. The parameter estimates are given in Table I. This model is valid for yeast extract and sucrose concentrations up to 10 and $50 \mathrm{~g} / \mathrm{L}$, respectively.

\section{Substrate Utilization Experimental Results}

During growth in sucrose media it is not known whether or not dextransucrase is the sole enzyme responsible for the
Table I. List of parameter estimates for specific growth rate model.

\begin{tabular}{cl}
\hline Parameter & \\
\hline$\mu_{\max }$ & $0.9 \mathrm{~h}^{-1}$ \\
$\alpha$ & $0.5 \mathrm{~g}$ sucrose $/ \mathrm{g}$ yeast extract \\
$K_{y e}$ & $0.3 \mathrm{~g} \mathrm{yeast} \mathrm{extract} / \mathrm{L}$ \\
$K_{s}$ & $2.5 \mathrm{~g} \mathrm{sucrose} / \mathrm{L}$ \\
\hline
\end{tabular}

production of fructose, glucose, and dextran, as depicted by Figure 6. L. mesenteroides bacteria may also produce other enzymes, such as invertase, that can catabolize sucrose to glucose and fructose for cell growth. The development of the kinetic model, however, can exclude the need to know the individual concentration of dextransucrase and invertase if one combines the effect of the enzyme(s) into a bulk enzyme activity measurement. Consequently, the effect of multiple enzymes is combined into a single bulk enzyme concentration (measured as an activity) that is responsible for dextran production and the liberation of glucose and fructose.

The results of the batch experiments for cell growth and free enzyme(s) activity are presented in Figure 9. As can be seen, the enzyme(s) activity matches the production of cells up to the time when the cells reach the stationary growth phase at which point the activity of the enzyme begins to decline. In general, the initial enzyme(s) activity is attributed to cellular enzyme generation when sucrose is abundant. There is a subsequent decrease in activity after the stationary phase occurs, because enzyme synthesis ceases, due to the lack of sucrose in the feed, and existing enzyme(s) degrade from toxic and thermal effects.

A series of batch growth experiments with varying initial monosaccharide concentrations were then carried out to determine the cell production yields on glucose and fructose after $24 \mathrm{~h}$ of growth. The cell production to substrate-consumption yields, for growth on the respective substrates, were calculated from the ratio of the final cell concentration to the initial substrate concentrations in the region of growth where the substrate had been exhausted. Cell growth on glucose and fructose has a cell production to substrate consumption ratio of $1.1 \times 10^{11}$ cells $/ g$ glucose and $9.9 \times 10^{10}$ cells $/ g$ fructose, respectively.

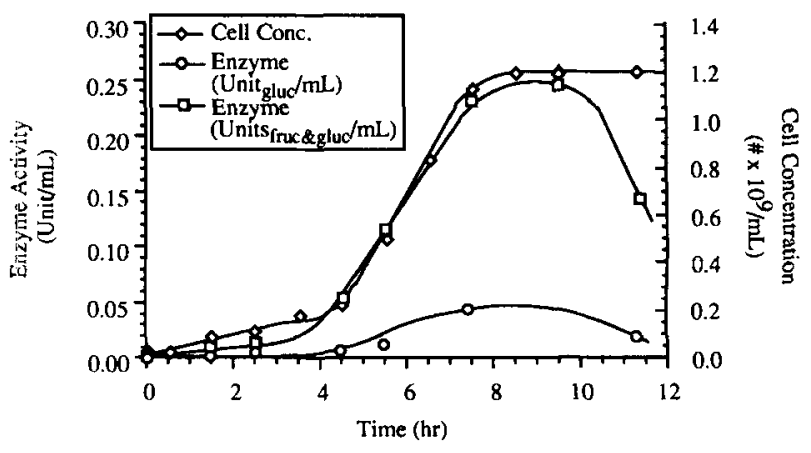

Figure 9. Enzyme and cell production during batch growth in $20 \mathrm{~g} / \mathrm{L}$ sucrose and $10 \mathrm{~g} / \mathrm{L}$ yeast extract. 


\section{Sucrose Utilization Model}

Sucrose, glucose, and fructose production and consumption balances for batch growth are:

$$
\begin{gathered}
\frac{d C_{s}}{d t}=-r_{d}-r_{g} \\
\frac{d C_{g}}{d t}=\gamma r_{g}-Y_{g / x} r_{x} \\
\frac{d C_{f}}{d t}=\gamma r_{d}+\gamma r_{g}-Y_{f / x} r_{x}
\end{gathered}
$$

where:

$r_{i}=$ the rate of species $i$ production $(\mathrm{g} / \mathrm{L} \cdot \mathrm{h}$ or cells/ $\mathrm{L} \cdot \mathrm{h}$ ).

$Y_{i}=$ cell yield from species $i$ consumption (cells $/ \mathrm{g}$ ).

$C_{i}=$ concentration of species $i(\mathrm{~g} / \mathrm{L}$ or cells $/ \mathrm{L})$.

$t=$ time (h).

$\gamma=0.5263$ (molecular weight ratio - monosaccharide to sucrose equivalent).

Subscripts for kinetic parameters are:

$$
\begin{array}{llll}
x & \text { cell. } & d & \text { dextran. } \\
e & \text { enzyme. } & g & \text { glucose. } \\
f & \text { fructose. } & s & \text { sucrose. }
\end{array}
$$

Using Lawford's model for dextran and glucose production $^{9}$ [Eq. (7)], the above equations along with the cell balance can be rewritten as:

$$
\begin{gathered}
\frac{d C_{x}}{d t}=\mu^{\prime} C_{x} \\
\frac{d C_{s}}{d t}=-\left(V_{\max _{d}}+V_{\max _{g}}\right)\left(\frac{C_{s}}{K_{d}+C_{s}}\right) \\
\frac{d C_{g}}{d t}=\gamma V_{\text {max }_{g}}\left(\frac{C_{s}}{K_{d}+C_{s}}\right)-Y_{g / x} \frac{d C_{x}}{d t} \\
\frac{d C_{f}}{d t}=\gamma\left(V_{\max _{d}}+V_{\text {max }_{g}}\right)\left(\frac{C_{s}}{K_{d}+C_{s}}\right)-Y_{f / x} \frac{d C_{x}}{d t}
\end{gathered}
$$

where:

$$
\begin{aligned}
K_{d}= & \text { Michaelis-Menten constant for sucrose utiliza- } \\
& \text { tion. } \\
\mu^{\prime}= & \text { corrected specific growth rate for growth retarda- } \\
& \text { tion (see Appendix II). }
\end{aligned}
$$

The nutrient balance equations assume that the maximal velocity for sucrose consumption is a function of the enzyme concentration ${ }^{4}$ as given by Eq. (17):

$$
V_{\max _{i}}=\theta_{i} \frac{k_{i}}{k_{f}} C_{e}
$$

where:

$k_{i}=$ activity of the enzyme per volume per cell to produce product $i$ at $30^{\circ} \mathrm{C}$ and $\mathrm{pH} 5.2$.

$\theta_{i}=$ dimensionless reaction rate constant for sucrose consumption at reaction temperatures.
$C_{e}=$ enzyme concentration responsible for fructose production.

The rate of enzyme production by the cells is modeled by the Leudeking and Piret equation. From the data presented in Figure 9, it is assumed that enzyme production rate, $r_{e}$, is strictly non-growth associated, and the enzyme production model can be written as:

$$
\frac{d C_{e}}{d t}=r_{e}=k_{f} C_{x}
$$

By assuming that the specific growth rate, $\mu^{\prime}$, is constant, the enzyme production equation can be integrated to give the following relation between cell growth and enzyme production:

$$
C_{e}=\frac{k_{f}}{\mu^{\prime}} C_{x} o\left(e^{\mu^{\prime} t}-1\right)
$$

From this equation, the activity of the enzyme, $k_{f}$, was estimated and is presented in Table II. Similarly, $k_{d}$ and $k_{g}$ can be estimated from the respective enzyme activity data for dextran and glucose production.

In the above model, only the reaction rate constants $\left(\theta_{i}\right)$ in Eq. (17) have not been defined. Using the data from a growth experiment that gave cell, saccharide, and dextran concentrations as a function of time allows for the determination of the reaction rate constants in the above model. These reaction rate constants are provided in Table II, and Figure 10 presents the model prediction for one particular set of growth conditions and compares the prediction with experimentally determined data.

\section{Polysaccharide Production Experimental Results}

The batch experiments used to quantify the specific growth rate results were also used to obtain insoluble dextran production data. The dextran production curves for four batch reactor experiments in Figure 11 show an increase in dextran yields with increases in the initial sucrose concentration. This result is expected because the rate of dextran production is dependent upon the concentration of sucrose provided in the media. ${ }^{9}$

\section{Polysaccharide Production Model}

Recalling Eq. (4), where dextran is synthesized at the expense of sucrose, the rate of dextran production can be

Table II. Parameter estimates for substrate utilization model.

\begin{tabular}{cc}
\hline Parameter & \\
\hline$\theta_{d}$ & $0.07 \mathrm{~g}$ sucrose $/ \mathrm{U} \cdot \mathrm{h}$ \\
$\theta_{g}$ & $1.23 \mathrm{~g}$ sucrose $/ \mathrm{U} \cdot \mathrm{h}$ \\
$k_{d}$ & $13.7 \mathrm{pUnits} / \mathrm{cell} \cdot \mathrm{h}$ \\
$k_{g}$ & $84.1 \mathrm{pUnits} / \mathrm{cell} \cdot \mathrm{h}$ \\
$k_{f}$ & $97.8 \mathrm{pUnits} / \mathrm{cell} \cdot \mathrm{h}$ \\
$K_{p}{ }^{\mathrm{a}}$ & $10.3 \mathrm{~g}$ sucrose $/ \mathrm{L}$ \\
\hline
\end{tabular}

${ }^{a}$ Based on Ebert ${ }^{2}$ and Lawford. ${ }^{9}$ 


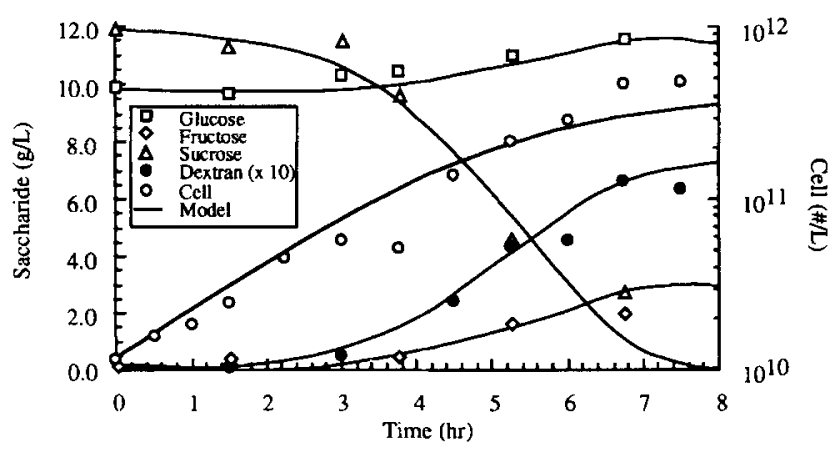

Figure 10. Predicted versus experimentally determined saccharide and cell concentration for batch growth.

equated with the rate of fructose liberated by the enzymes according to:

$$
\frac{d C_{i d}}{d t}=Y_{i d / d} r_{d}
$$

where

$$
\begin{aligned}
Y_{i d / d} & =\text { insoluble to total dextran production yield. } \\
C_{i d} & =\text { insoluble dextran concentration }(\mathrm{g} / \mathrm{L}) .
\end{aligned}
$$

Note that the above model excludes fructose liberated during glucose production, as given by Eq. (5). The ratio $Y_{\text {idld }}$ was estimated as 0.24 insoluble dextran from the polysaccharide production batch experiments. In addition to di- and monosaccharide consumption/production, Figure 10 presents the model prediction for dextran production.

According to the stoichiometry of reaction 4 , the expected value of $Y_{\text {id/d }}$ is $1.0 \mathrm{~g}$ dextran $/ \mathrm{g}$ fructose if all of the dextran produced is insoluble. However, dextran is a biopolymer that initially develops from a monomer into a polymer containing typically over 100,000 monomer units. ${ }^{2}$ This change in polymer length alters the chemical properties of the polymer molecule from soluble to insoluble. Thus, a value of $0.24 \mathrm{~g}$ dextran $/ \mathrm{g}$ fructose for $Y_{i d / d}$ implies that $76 \%$ of all the dextran produced is soluble.

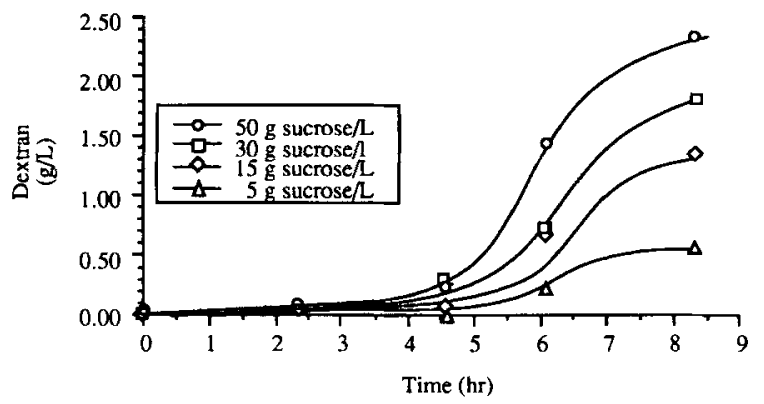

Figure 11. Dextran production on media containing 5, 15, 30, and $50 \mathrm{~g}$ sucrose $/ \mathrm{L}$ and $0.5 \mathrm{~g}$ yeast extract/L.

\section{Manipulation of Nutrient Feed for Plug Control}

As illustrated by the core plugging experiments, the plugging of porous media by in situ bacterial growth is dependent upon the cell's ability to produce polysaccharide. In addition, results from core staining ${ }^{8}$ have shown that the movement of cells within porous media is influenced by the cell's ability to produce polysaccharides. Hence, cell transport and retention in porous media can be facilitated by controlling the cell's ability to produce polysaccharide. Controlling bacteria production of polymers is accomplished by controlling the ratio of macronutrients such as nitrogen and phosphorous to carbon. ${ }^{3}$ Because yeast extract provides the $L$. mesenteroides bacteria with the needed macronutrients, such as nitrogen and phosphorous, altering the ratio of yeast extract to sucrose would influence the amount of polymer produced per cell. Figure 12 shows the results from two simulations of model growth at an initial sucrose concentration of $50 \mathrm{~g} / \mathrm{L}$ with varying yeast extract concentrations. As seen from the predictions, dextran production per cell increases as the amount of yeast provided decreases. The model predicts a higher dextranto-cell production rate when the yeast extract concentration is lowered, because yeast extract influences the cell growth rate but not the dextran production rate. Thus, varying the ratio of yeast extract to sucrose in the feed allows for the manipulation of the dextran to cell production rate and influences the rate of permeability decline of a porous medium.

It has been demonstrated experimentally that the permeability of porous media, as affected by in situ growth, can be controlled via the feed ratio of yeast extract to sucrose. Figure 1 shows that a 1000 -fold decline in core permeability was achieved after $40 \mathrm{~h}$ of feeding an inoculated porous media with $15 \mathrm{~g}$ sucrose/L and $2 \mathrm{~g}$ yeast extract/L (feed recipe listed Table A-I). These results are in contrast to in situ growth experiments where an inoculated porous media was fed only $5 \mathrm{~g}$ sucrose/L (other feed components being the same) and no measurable permeability decline occurred during the $60 \mathrm{~h}$ of feed injection. The different permeability responses may be due to: differences in the total number of cells generated in situ if one uses sto-

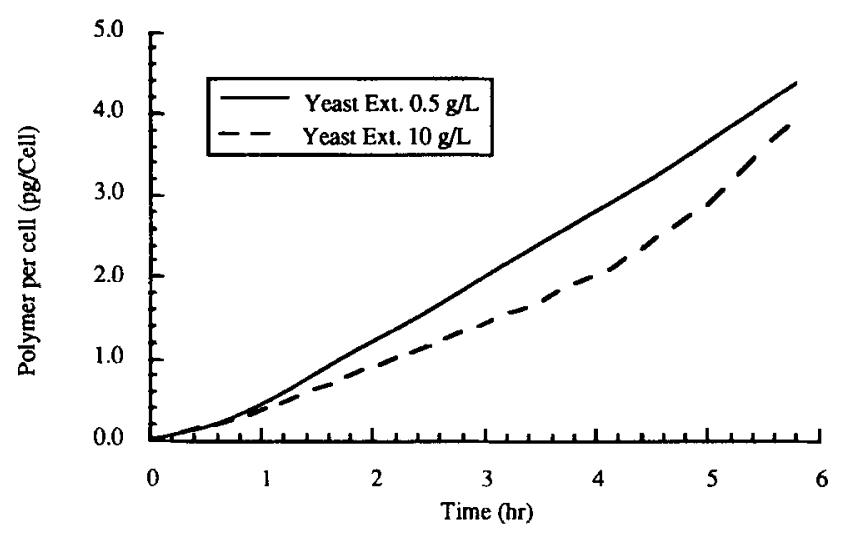

Figure 12. Dextran production per cell on media containing $50 \mathrm{~g}$ sucrose/ $\mathrm{L}$ and 0.5 and $10 \mathrm{~g}$ yeast extract/L (simulation results). 
ichiometry as a basis for cell number determination; or differences in the amount of polysaccharide production per cell. Proving that the permeability responses are the result of polysaccharide production can be shown by using the kinetic model in the following manner:

1. The overall permeability of porous medium depends upon local or regional permeabilities in a manner that any changes in the local permeability strongly influences the overall permeability.

2. In situ growth experiments exhibited the highest changes in internal cell concentrations at the injection face during feeding..$^{5}$ Because the local permeability is reduced as the local porosity is reduced by cell and polysaccharide generation, the local permeability at the injection face region will thus have the greatest influence on the overall permeability of the porous medium.

3. Determination of the cell and polysaccharide production rate are possible by assuming that nutrients are not consumed at a sufficient rate as to decrease their concentration dramatically in the injection zones.

For the two experiments discussed above, the cell's growth rates at the respective injection faces are approximately the same (specific growth rates are $0.72 \mathrm{~h}^{-1}$ for $5 \mathrm{~g}$ sucrose/L and $0.8 \mathrm{~h}^{-1}$ for $15 \mathrm{~g}$ sucrose/L) as predicted by the kinetics. However, the predicted rates of polysaccharide production show an increase of almost a factor of two when sucrose is increased from 5 to $15 \mathrm{~g}$ sucrose/L. Hence, the kinetic model predicts the qualitative experimental results that polysaccharides cause the reduction of the porous media permeability. Predicting the permeability reduction responses for each of the experiments as a function of time, however, requires the use of bacteria capture model whether the model be based on stochastic or continuum theory, in conjunction with an in situ growth model. With such a model an injection strategy can be developed for BPM.

\section{CONCLUSIONS}

A model for the growth kinetics of $L$. mesenteroides on sucrose has been developed. The model reflects experimental results that show both the yeast extract and sucrose concentrations affect cell growth rate. Sucrose is used by cells as a carbon source, whereas yeast extract primarily provides the cells with needed growth factors for cell enzyme synthesis. Batch experiments have shown that sucrose is consumed at a faster rate than glucose or fructose, and cell growth on a glucose-fructose media has not shown any preference for either monosaccharide. This results supports the hypothesis that the cell is externally catabolizing the sucrose to produce dextran, glucose, and fructose, and that the monosaccharides are then transported into the cell for growth. A substrate utilization mechanism has been created and used to develop a the specific growth rate model. The insoluble dextran production experiments have demonstrated that final polymer production yields are dependent upon the availability of sucrose in the feed. These results can be modeled by equating dextran production with fructose production during dextran synthesis. Final model predictions show that the dextran (polysaccharide)-to-cell production ratio can be altered by controlling the yeast extract to sucrose feed ratio. Controlling the amount of dextran produced per cell will be useful in the development of an injection strategy for $L$. mesenteroides for bacterial profile modification.

The authors thank the Industrial Affiliates Program at the University of Michigan-Flow and Reaction in Porous Media, and the Department of Energy, under contract Cooperative Agreement DE-AC22-90BC14664.000, for funding this work. In addition the authors appreciate the comments presented by Terri Stewart during the preparation of this paper.

\section{NOMENCLATURE}

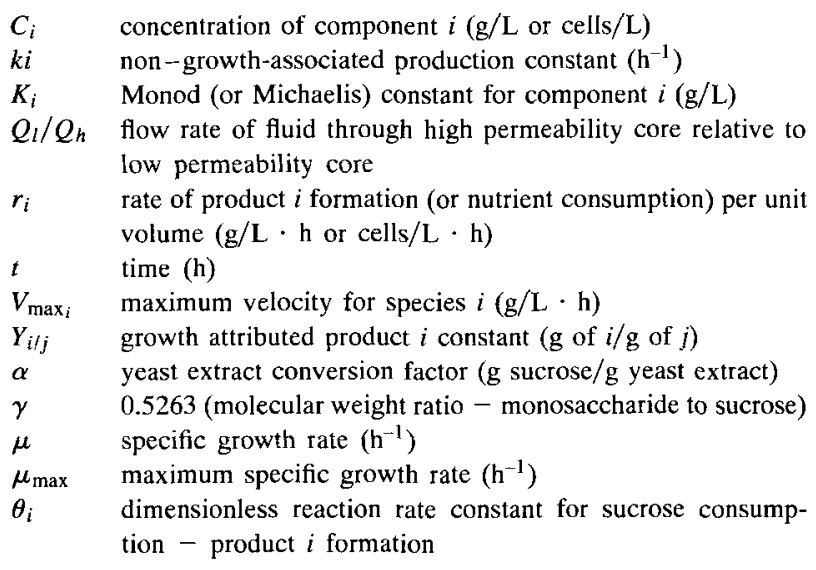

$\begin{array}{ll}\text { Subscripts } \\ \boldsymbol{x} & \text { cell } \\ e & \text { enzyme } \\ f & \text { fructose } \\ m & \text { monosaccharide } \\ d & \text { dextran } \\ g & \text { glucose } \\ s & \text { sucrose } \\ y e & \text { yeast extract }\end{array}$

\section{APPENDIX I}

Table A-I. Medium for carbohydrate experiments.

\begin{tabular}{lc}
\hline Tap water & $1000 \mathrm{~mL}$ \\
Tryptone (Difco) & $20 \mathrm{~g}$ \\
Yeast extract (Difco) & $5 \mathrm{~g}$ \\
$\mathrm{NaCl}$ & $4 \mathrm{~g}$ \\
Sodium acetate & $1.5 \mathrm{~g}$ \\
Ascorbic acid & $0.5 \mathrm{~g}$ \\
Trace elements (Ca, Mn, Fe, Mg) & $\sim 10^{-4} \mathrm{M}$ each \\
& \\
Carbohydrates & \\
Sucrose & $15 \mathrm{~g}$ \\
Fructose & $7.9 \mathrm{~g}$ \\
Glucose & $7.9 \mathrm{~g}$ \\
\hline
\end{tabular}

Yeast extract (and tryptone) are supplied to the cells as the sources of amino acids, purines, pyrimidines, and vitamins, which are needed by the cells for growth, because Leuconostoc cells cannot synthesize these compounds for themselves. ${ }^{11}$ 
Table A-II. Medium for kinetic experiments.

\begin{tabular}{lc}
\hline Tap water & $1000 \mathrm{~mL}$ \\
$\mathrm{NaCl}$ & $4 \mathrm{~g}$ \\
Sodium acetate & $5 \mathrm{~g}$ \\
Ascorbic acid & $0.5 \mathrm{~g}$ \\
Potassium phospate (dibasic) & $1 \mathrm{~g}$ \\
Trace elements & $-10^{-4} \mathrm{M}$ each \\
$\mathrm{Ca}, \mathrm{Mn}, \mathrm{Fe}, \mathrm{Mg}$ & \\
Yeast extract (Difco) & Varied \\
Sucrose & Varied
\end{tabular}

\section{APPENDIX II}

When comparing the kinetic model to the batch growth data for cell growth on sucrose and glucose (see Fig. 5), it was noted that the predicted specific growth rate was overestimated by Eq. (9). This discrepancy is due to the transfer of toxins with the inoculum in this batch experiments. The inoculum used for this experiment, for which the results are also presented in Figure 10, was not separated from the initial growth media, and thus toxins were transferred that impeded the cell growth.

A growth retardation model has been used to account for the effect of toxins on the specific growth rate and is defined by Eq. (II-1):

$$
\mu^{\prime}=\mu\left(C_{s}, C_{y e}\right)\left(1-\frac{C_{x}}{C_{x_{\max }}}\right)
$$

where

$$
\begin{aligned}
\mu\left(C_{s}, C_{y e}\right) & =\text { the specific growth rate [given by Eq. (9)]. } \\
C_{x_{\max }} & =\text { maximum cell concentration. }
\end{aligned}
$$

$C_{x_{\max }}$ was estimated from the batch data for cell growth as $4.2 \times$ $10^{11}$ cells/L.

\section{References}

1. Chaplin, M.F., Kennedy, J.F. 1986. Carbohydrate analysis. IER Press, Oxford, England.

2. Ebert, K. H., Schenk, G. 1968. Mechanisms of biopolymer growth: the formation of dextran and levan, pp. 179-221. In: F. F. Nord (ed.), Advances in enzymology and related areas of molecular biology. International Publishers, New York.

3. Evans, C. G.T., Yeo, R.G., Ellwood, D. C. 1979. Continuous culture studies on the production of extracellular polysaccharides by Xanthomonas juglandis, pp. 51-68. In: R. C.W. Berkeley, G.W. Gooday, and D.C. Ellwood (eds.), Microbial polysaccharides and polysaccharases. Academic Press, New York.

4. Fogler, H. S. 1992. Elements of chemical reaction engineering. 2nd edition. Prentice-Hall, Englewood Cliffs, NJ.

5. Geesey, G. G., Mittelman, M. W., Lieu., V.T. 1987. Evaluation of slime-producing bacteria in oil field core flood experiments. Appl. Environ. Microbiol. 53: 278-283.

6. Jack, T. 1982. The potential for use of microbes in the production of heavy crude. In: Proceedings of International Conference on Microbial Enhancement of Oil Recovery. Shangri-La, Afton, OK, May 16-21.

7. Lappan, R.E. 1993. Reduction of porous media permeability from in situ bacterial growth and polysaccharide production, Ph.D. thesis, University of Michigan, Ann Arbor, MI, USA.

8. Lappan, R. E., Fogler, H.S. 1992. Effect of bacterial polysaccharide production on formation damage. Soc. Pet. Eng. J. 7: 167-171.

9. Lawford, G. R., Klingerman, A., Williams, T. 1979. Dextran biosynthesis and dextransucrase production by continuous culture of $\mathrm{Leu}$ conostoc mesenteroides. Biotechnol. Bioeng. 21: 1121-1131.

10. Leudeking, R., Piret, E. L. 1959. A kinetic study of the lactic acid fermentation. J. Biochem. Microbiol. Technol. Eng. 1: 393-412.

11. Stanier, R. Y., Ingraham, J.L., Wheelis, M. L., Painter, P.R. 1986. The microbial world. 5th edition. Prentice-Hall, Englewood Cliffs, NJ. 